\title{
Biografía de un concepto
}

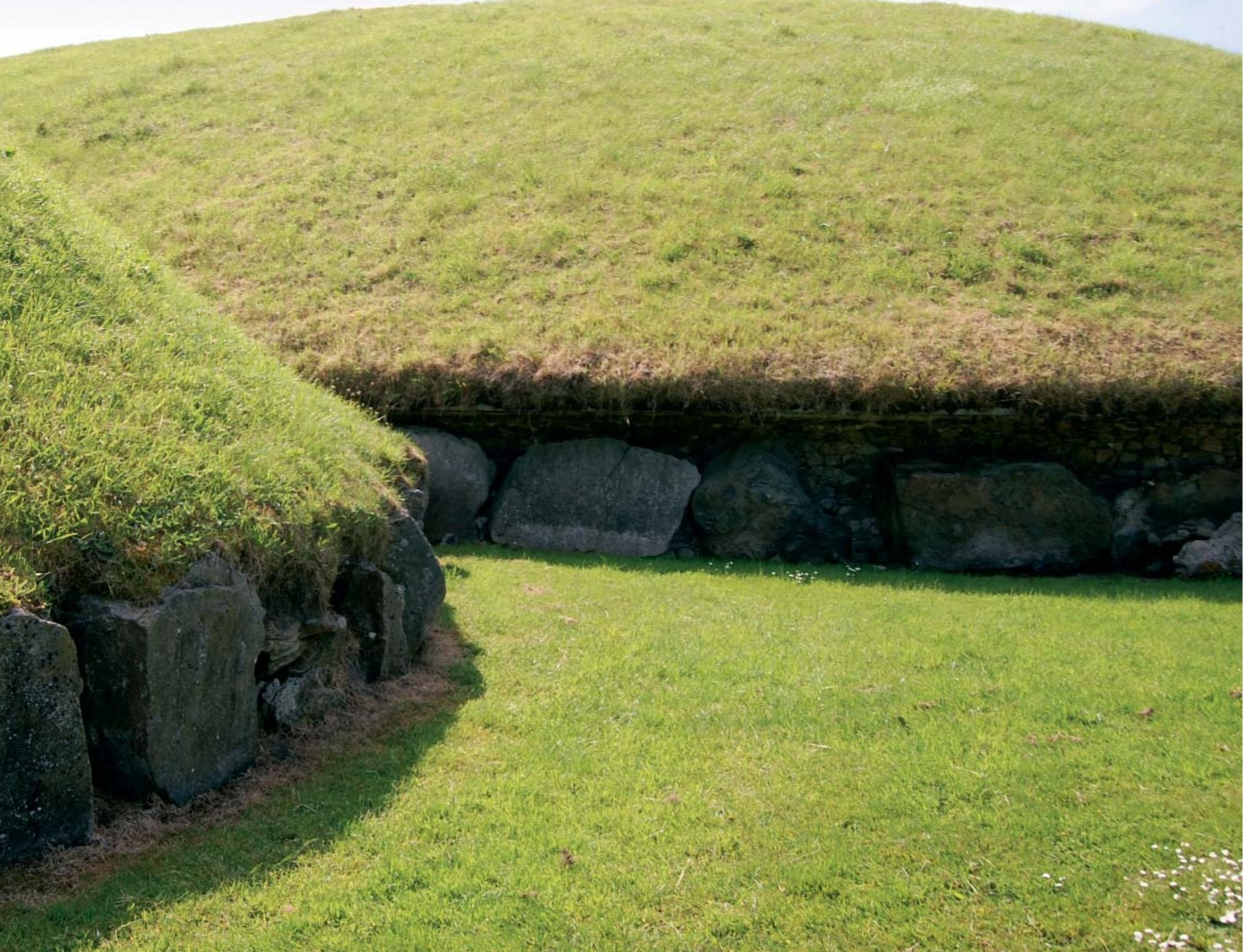


El primer problema al que nos enfrentamos cuando estudiamos el fenómeno megalítico es su caracterización, dificultada por las ideas consolidadas en el imaginario colectivo. En este sentido la fascinación ejercida por el fenómeno puede rastrearse bastante atrás en el tiempo. En primer lugar, los monumentos prehistóricos siguieron siendo usados hasta nuestra era y, en segundo lugar, en ésta fue frecuente la referencia mítica a los monumentos y su construcción, como ejemplifica la relación de Stonehenge (Reino Unido) con el ciclo artúrico. La vinculación del folklore con la investigación puede apreciarse en la proliferación de nombres locales y tradicionales en la bibliografía científica (dolmen, anta, menhir, crómlech, mamoa, tomba di giganti, etc.), algunos de ellos implicando funciones determinadas que, a menudo, han sido confirmadas por la investigación. En cualquier caso ésta ha debido clarificar cuatro aspectos: la definición de los elementos que pueden considerarse megalíticos, su origen, su cronología y su función. Aunque es indudable que existe una cierta correlación entre las respuestas dadas por los investigadores a cada uno de ellos también es cierto que la persistencia en el desacuerdo justifica un desarrollo historiográfico autónomo.

En la definición del fenómeno megalítico se han empleado tradicionalmente dos criterios: por un lado, la utilización de grandes piedras y, por otro, la presencia del ritual de inhumación colectiva. Dentro del primer criterio se incluyen no sólo las sepulturas dolménicas (básicamente en forma de cajas) sino otras manifestaciones como las piedras enhiestas de sección aproximadamente fálica (menhires) y sus agrupaciones lineales (alineaciones) o circulares (crómlechs o henges). El principal problema, sin embargo, es que estos de monumentos realizados con grandes piedras se extienden por una gran parte del globo y han sido realizados incluso en épocas muy recientes. Además determinadas manifestaciones rituales de la Prehistoria Reciente europea (entre el V y el II milenio a. de C.) fueron construidas sin emplear grandes piedras, a partir de estructuras de mampostería (como los denominados tholoi, estén cubiertos o no con falsa cúpula) o de madera, excavando la roca (cuevas artificiales o recintos delimitados por fosos) o aprovechando cavidades naturales, sin que falten monumentos realizados con varias técnicas, especialmente revestimientos de grandes piedras (ortostatos) o cimentaciones que adquieren un verdadero carácter hipogeico. La segunda acepción no carece tampoco de problemas ya que bajo el término enterramiento colectivo se incluyen modos de deposición variados. Así en unos casos se introducían periódicamente muertos arrinconando los restos anteriores y, en otros, los muertos, a veces en masa, se introducían simultáneamente.

Además de diferenciar los monumentos según su función (básicamente sepulturas y otros recintos rituales) o su técnica constructiva, incluso dentro de los dólmenes se pueden hacer distinciones, a partir de la forma y dimensiones de la colina artificial que los cubría (el túmulo), o por las características de los elementos interiores, básicamente la cámara (el principal contenedor funerario) y el corredor, pudiendo este último estar ausente y existiendo formas avanzadas de fusión entre ambos elementos, las denominadas galerías. Las formas de las cámaras (rectangulares, trapezoidales, circulares, etc.) han sido utilizadas, junto con la presencia o no de corredor o del ritual de inhumación colectiva, como argumento genético o cronológico.

Los primeros trabajos científicos sobre el megalitismo exaltaron, por un lado, las grandes obras (monumentos) como expresión de un determinado nivel social y ciertas creencias y, por otro, recurrieron a la idea de progreso para explicar su evolución. En este sentido se comprende que los megalitos fueran objeto de temprana atención incluso en la Península Ibérica, aunque las interpretaciones estuvieran lastradas del pensamiento mítico y de la poca profundidad temporal (templos druidas por ejemplo), si bien rápidamente se les consideró una de las mejores manifestaciones de los contactos entre las comunidades prehistóricas y, específicamente, de la influencia de las "grandes civilizaciones" orientales 
(colonos). En este sentido el megalitismo desde fines del siglo XIX se convirtió en uno de los mejores ejemplos argüidos por los arqueólogos histórico-culturales para probar la difusión de la civilización. Se afirmaba la improbabilidad de una invención autónoma en diferentes áreas y se relacionaban las similitudes con un origen común, habitualmente localizado en el Próximo Oriente, y una difusión progresiva desde esta área nuclear. Las diferencias entre los autores no estribaban en la crítica a esta visión general sino en el punto de origen identificado (incluso con posturas occidentalistas), en las formas de la difusión (comerciantes, misioneros, prospectores metalúrgicos, etc.) y en los elementos concretos a los que afectaba ésta (la arquitectura, la cultura material mueble, el ritual de inhumación colectiva, etc.). Para los intereses imperialistas (satisfechos o no) no importaba mucho si la esencia nacional era la herencia de un pueblo sin mezclas étnicas, inalterable a lo largo del tiempo, o procedía de múltiples aportes civilizadores en una historia rica en mezclas de pueblos; desde ambas posturas se podía justificar la alta labor que esperaba a estas potencias nacionales, imponiendo por el bien de los demás su superioridad.

Estas preocupaciones, sin embargo, chocan con el escepticismo empirista que dominará cuando el difusionismo, y la justificación nacionalista que perseguía, entren parcialmente en crisis tras la Segunda Guerra Mundial, abandonándose los intentos de identificación étnica, aunque proliferen los catálogos, y quedando reducida la "interpretación" al movimiento de los objetos, en algunos casos multi-direccional, en un contexto de creciente valoración de las diferencias, al que no es ajena la descolonización. Por un lado, la extensión de las dataciones de radiocarbono a partir de la década de los 1970 (y especialmente su calibración en la de los 1990), desmanteló la teoría del origen oriental de los monumentos megalíticos europeos. Por otra parte, las dificultades para identificar una o varias áreas nucleares en el occidente europeo obligaron a desarrollar nuevos modelos explicativos sobre el surgimiento y/o adopción de la "moda" megalítica en los que los precedentes mesolíticos adquirieron especial importancia. La lentitud en la introducción de nuevos esquemas teóricos (en su mayor parte funcionalistas y procesualistas) y el prestigio de muchos de los investigadores difusionistas retardó la entrada de nuevas explicaciones que, en cualquier caso, afectaron no sólo al origen sino también a la cronología y la función de los monumentos megalíticos.

La mayor parte de las primeras interpretaciones de los años setenta y ochenta del siglo pasado, situadas en un marco teórico funcionalista y neoevolucionista, adoptan una estrategia determinista que sitúa las causas últimas de la transformación al exterior del sistema social (el cambio climático y la presión demográfica) y que, al negarse a contemplar los contactos culturales, era incapaz de explicar, más allá de la generalidad de la fácil comunicación marítima atlántica, por qué la función de afirmación de la cohesión social atribuida a estos monumentos se concretó en manifestaciones tan similares, aunque haya que reconocerles el mérito de reclamar la importancia de estos elementos como marcadores territoriales.

Además, en ausencia de datos sobre los asentamientos, los monumentos megalíticos fueron utilizados desde los años setenta del siglo pasado para deducir estrategias económicas y áreas de explotación económica. Los principales problemas, además de que la presencia de un recurso no implica su utilización, se encuentran cuando se realiza una oposición simplista entre agricultores sedentarios y pastores nómadas, una opción muy extendida en los estudios realizados sobre la Península Ibérica, compartimentando sin razón el territorio. Por el contrario otros autores han llamado la atención sobre la dispersión de los megalitos de la montaña al Ilano marcando rutas de desplazamiento e incluso escenarios rituales relacionados con la domesticación del ambiente que implican la definición diferencial de las áreas de asentamiento permanente/explotación intensiva y las de explotación extensiva.

Sin embargo, muchos de los nuevos planteamientos sobre el origen del megalitismo arrastran una fuerte carga idealista al preocuparse, en el marco del posmodernismo imperante en los albores del siglo XXI, más de la percepción (individual) que se tuvo (y se tiene) de los monumentos rituales que de la función de éstos en la sociedad. En cualquier caso los estudios concretos, más que las reflexiones teóricas, están llenos de contribuciones válidas que en la interpretación del origen del megalitismo han resaltado la función de las tumbas con expresión del dominio ejercido sobre la naturaleza y sobre otros hombres con el desarrollo agropecuario neolítico (y la resistencia de éstos) y el papel que en determinadas zonas adquieren como marcadores de la identidad. En el fondo no existe una ruptura radical con el procesualismo en la lectura final y ni siquiera en los detonantes (tecnológicos o demográficos) y aunque se demanden interpretaciones de casos particulares en el fenómeno que nos ocupa tienden a reproducirse las generalidades que olvidan en muchos casos los precedentes de enterramientos mesolíticos, aunque afortunadamente se destaquen aspectos como el dominio y la función de la ideología.

En relación con el tercer problema citado al comienzo, debemos señalar que, aunque es indudable que existen importantes dificultades para establecer las relaciones cronológicas entre los monumentos y sus contenidos a no ser de forma muy general, las primeras sepulturas megalíticas no parecen estar relacionados con el enterramiento colectivo y cuando se produce éste existen problemas para determinar si la introducción de los cadáveres fue a veces simultánea o si la tumba fue usada durante un largo período de tiempo, en un contexto que a veces implicaba todo un conjunto de prácticas como fiestas fúnebres largas, amontonamiento, limpieza y arrinconamiento de restos anteriores y traslados entre cáma- 
ras o entre diferentes monumentos. Otro argumento cronológico a tratar es la evolución de los contenedores, desde los más simples, con cámaras ortogonales sin corredor, a los más complejos, aunque dataciones como las de Barnenez (Bretaña, Francia) parecen contradecir esta tendencia.

En cualquier caso es indudablemente difícil datar estas estructuras, ya que ni la datación de los paleosuelos (situados bajo ellos) ni la de los contenidos asegura el momento de construcción del sepulcro, que pudo estar en uso durante un periodo muy prolongado y que pudo sufrir modificaciones que afectaron incluso a sus elementos estructurales, lo que obliga a ser cautos incluso si se cuenta entre ellos con elementos que se puedan datar (vigas o postes).

Hipótesis recientes tienden a explicar el megalitismo como una forma de expresar y enmascarar las desigualdades que se van produciendo en la sociedad, desde la acentuación de la explotación de las mujeres y los niños que acompaña al Neolítico, hasta la presión sobre comunidades vecinas o el desarrollo de las clases sociales. De hecho, de las tres funciones profundamente relacionadas que puede desempeñar el ritual como formalización de la ideología (afirmación de la propiedad, fomento de la cohesión social y exhibición o enmascaramiento de la desigualdad) sólo en los últimos años, y poco frecuentemente, se ha puesto el acento sobre la última, refiriéndose el conflicto y la renegociación del poder. En esta línea el enterramiento colectivo ha sido considerado un enmascaramiento dado que sucede a las primeras inhumaciones individuales, que no es un ritual exclusivo en ningún momento como muestra el número reducido de inhumaciones en grandes sepulcros como Knowth o Newgrange en el valle del Boyne (co. Meath, Irlanda) y que oculta una amplia variedad de manifestaciones. Además de contenidos más o menos suntuarios, el aspecto fundamental que se resalta es el de la monumentalidad, conferida especialmente por los túmulos, dado que dificulta la emulación y, por tanto, al mismo tiempo que proyecta el mensaje hacia el futuro dificulta su modificación. Se ha referido que se excluía a determinados sectores de la comunidad de la interpretación-justificación de la sociedad a través de la perpetuación ideológica del pasado por el culto a los ancestros (cuyos restos se manipulaban continuamente) o por la reinterpretación de eventos astronómicos, a partir de la ocultación en determinadas secciones de los monumentos de los sonidos (narraciones), signos grabados y movimientos (ceremonias).

Concluyendo se puede señalar que, tras el tratamiento mítico tradicional, con el nacimiento de la Arqueología como ciencia, los megalitos se concibieron en primer lugar como expresión del desarrollo alcanzado por los pueblos prehistóricos europeos en el marco del evolucionismo imperante hasta avanzado el siglo XIX para, posteriormente, con el auge del imperialismo pasar a ser explicados en el marco del movimiento de pueblos e ideas que se suponía que había tenido lugar en la Prehistoria.

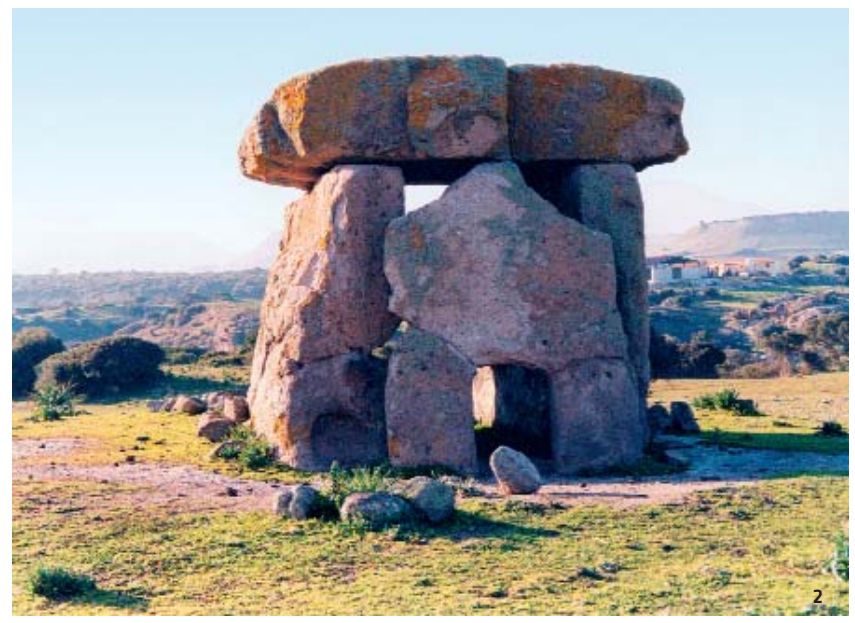

En cualquier caso no hubo particulares cambios de rumbo en la interpretación real de los monumentos megalíticos dado que se prestó especial atención a su tipología y contenidos para relacionarlos con esquemas evolutivos en el primer caso o con desplazamientos de pueblos en el segundo, sin desarrollarse verdaderas explicaciones sobre su función o las causas de su presunta expansión, con notables excepciones como las diversas propuestas de V.G. Childe. La ausencia de explicación se acentuó cuando las interpretaciones étnico-políticas quedaron marcadas por los excesos del nazismo, hasta el punto de que los monumentos quedaron como objeto de estudio para el mero goce estético en el marco del escepticismo empirista de los nuevos anticuarios. Sin embargo la entidad de los elementos estudiados obligaba a algunas consideraciones sociales, ausentes del estudio contemporáneo de otras manifestaciones arqueológicas, perviviendo además la explicación difusionista. Ésta sólo decayó cuando se generalizaron las dataciones pero, para avanzar hacia el resurgir científico de la disciplina, era necesario un nuevo marco teórico que fue proporcionado por la Arqueología Procesual a partir de los años sesenta del siglo XX. En el marco de ésta el estudio de los megalitos se inscribió en la concepción funcionalista de la cultura y por ello, buscando su función, se enfatizó su papel en el mantenimiento del equilibrio y la cohesión social. Independientemente de la vertiente justificativa en sus objetivos y determinista en sus planteamientos que dirigía estos estudios, el principal problema es que favorecieron la proliferación de interpretaciones que fragmentaban la realidad megalítica, en el marco de la contradicción de una corriente que buscando explicaciones universales fomentaba los estudios microregionales. Finalmente la reacción anti-determinista desde la doble perspectiva, no siempre fácil de deslindar, del materialismo histórico y de la llamada Arqueología Posprocesual puso en primer plano la función ideológica de los megalitos y su relación con el conflicto social, aunque a menudo condujo a posiciones perspectivistas y presentistas. 